\title{
The effect of the economic crisis on the functioning of families with language-disordered children
}

\author{
Vlassopoulos $\mathbf{M}$ \\ Community Mental Health Centre Byron-Kessariani \\ 1st Department of Psychiatry, University of Athens School of Medicine \\ Chavele N \\ Community Mental Health Centre Byron-Kessariani \\ 1st Department of Psychiatry, University of Athens School of Medicine \\ Kontopoulou F \\ Community Mental Health Centre Byron-Kessariani \\ 1st Department of Psychiatry, University of Athens School of Medicine \\ Lazaratou $\mathbf{H}$ \\ Community Mental Health Centre Byron-Kessariani \\ 1st Department of Psychiatry, University of Athens School of Medicine
}

\begin{abstract}
Economic crises worldwide impact mental health. Job insecurity and consequent distress and uncertainty, affect the family and its functioning. The study's purpose is to compare the psychosocial outcomes for the families of children with specific developmental disorders (SDD) during two time periods: a) before the commencement of the economic crisis in Greece $(\mathrm{N}=22)$, b) during the economic crisis $(\mathrm{N}=25)$. Data consists of child's diagnosis, parents' age, educational level and professions, and the family's psychosocial diagnoses (ICD-10, 1991). Results show that Group B has significantly more problems related to the child's upbringing $(p=0.0163)$ : insufficient parental control and supervision, hostile behaviour towards the child, emotional neglect and difficulties in sustaining boundaries. In conclusion the emotional and practical difficulties elicited by the economic crisis appear to have a direct impact on families of SDD preschoolers. The findings highlight the need for focused interventions through community services to deal with this issue.
\end{abstract}

Key words: specific developmental disorders; psychosocial outcomes; family; economic crisis

INTRODUCTION

Greece is a country, which has undergone notable socio-economic vicissitudes in the last fifteen years. Specifically, in 2002 Greece had the highest rate of economic development among the EU countries, joined the Euro currency zone and was preparing for the 2004 Olympic Games, a series of positive events. On the contrary, in 2009 Greece experienced its worst financial crisis of the last decades and now has the largest recession among the EU countries, which has resulted in the intervention of the International Monetary Fund and the danger of imminent bankruptcy.

The present crisis has caused reductions in family income, high unemployment and generalized uncertainty concerning the future. The average family is forced to drastically restrict its expenses due to reduced salaries and pensions. Shops and businesses have shut 
down and new heavy taxation has been introduced, leading to a lack of societal cohesion, which is significant for well-being and quality of life. Anger and frustration are prevailing sentiments, as citizens criticize governmental choices and as economic inequality becomes all the more blatant. In the health sector, the financial difficulties have led to a cut in spending in health care services, and particularly reduced prevention. Moreover, access to healthcare has become more difficult as the families' assets are reduced.

Many studies over the past few years have noted that the economic crisis has severe negative repercussions on mental health (Chatterjee, 2009, Friedman \& Thomas, 2009, Paul \& Moser, 2009) Studies conducted on adult populations have demonstrated that economic hardship, such as low income and unemployment, affects adults' mental health in general and increases the levels of death rates, depression, and suicide tendencies (Chang et al 2013, Lee et al 2010).

The correlation between economic deprivation and depression has repeatedly been found and financial debt appears to be a particularly important factor predisposing to depression (Butterworth, Rodgers, \& Windsor, 2009). In Europe, a 1\% increase in unemployment rates is associated with an increase of $0.8 \%$ in suicides and of $0.8 \%$ in homicides, while an increase of more than $3 \%$ of unemployment rates is associated with an increase of more than $4 \%$ in suicides and deaths from alcohol abuse (Stuckler et al 2009).

In Greece, in recent years many studies have reached similar conclusions, confirming that the economic crisis and its consequences on employment, income and cuts in health benefits has a negative impact on mental health (Bouras \& Lykouras 2011, Giotakos et al 2011, Giotakos et al 2012, Economou \& Mavreas, 2011, Economou et al 2012).

Giotakos et al (2011) note that the increase of unemployment rates and the reduction in the average income appears to be related with the increase in referrals at outpatient and emergency departments in the main psychiatric hospitals of the country.

The economic crisis also has an impact on family functioning. In particular when parents are unemployed, they experience ambivalent feelings in relation to their family which are manifested by irritability and interfamilial conflicts (Fatourou, 2010). In addition to indebted households with difficulties in coping with everyday life, families who are not so financially distressed are also emotionally affected. The self-image and self-confidence of contemporary humans is largely determined by labour and financial standing. Increasing wage cuts, unstable forms of contractual employment, poor working conditions, income uncertainty and job insecurity have a negative impact on people's emotional resilience (Bouras \& Lykouras, 2011). It appears that the uncertainty and fear of unemployment contributes more than the job loss itself on the manifestation of depression (Ferrie et al. 1998, Meltzer et al. 2010).

In the case of families with children, this situation seems to affect the marital relationship, the mental state of the parents and family life, and these parameters appear to be directly related to the mental health of their children (Solantaus et al, 2004). The feeling of uncertainty and insecurity that pervades the adults could not leave the children and adolescents unaffected. The whole family is affected by the crisis and experiences feelings of hopelessness and helplessness (Anagnostopoulos \& Soumaki, 2012).

A survey by the Greek University Mental Health Research Institute, which covers the years 2006 and 2011, shows an increase of interfamilial conflict and a diminished ability in both the 
family and the school to manage even mild disruptive / aggressive behaviours of children (Chalkousi et al, 2012). The authors observe that the users of mental support services, who are experiencing uncertainty about the present and the future, have a clear need for understanding and guidance.

Child abuse and the family's socioeconomic profiles are correlated in several studies. The family's low economic status is associated with problematic parenting skills and child abuse. Numerous studies highlight the relationship between attachment difficulties and the family's economic problems. Melchior et al (2010) have reported child and adolescent psychological disorders in families whose financial difficulties persist and aggravate over time in a French community. Secure attachment is less easily implemented when attentive and responsive parenting is influenced negatively by stressful factors related to low income than when the families have a better socio-economic status. Parents may become more punitive, less available and less consistent due to psychological difficulties resulting from their financial problems (Gabarino, 1992, Belsky et al, 1991, Belsky 1993).

Since the beginning of the economic crisis, the number of difficulties of a psychosocial nature which are addressed at the Child and Adolescent Mental Health Unit in the Community Mental Health Centre Byron-Kessariani. has increased considerably. This paper attempts to shed light on the consequences of the economic crisis on the functioning of families of whom one or more members present specific developmental language and motor coordination disorders and who follow a treatment programme in our Service.

\section{METHODS}

The participants of this study consist of families with children with specific developmental disorders, inhabitants of four Athenian boroughs, served by the Child and Adolescent Mental Health Unit of the Community Centre (a department of the Athens University Medical School). The majority of the inhabitants have a low to moderate SES. The Community Centre is part of the National Health System and its services are provided free of charge. One of the services of this centre is the Early Intervention Programme (EIP) for children with specific developmental language and motor coordination disorders. The programme consists of diagnostic and intervention services to preschool children and their families.

Participants: The first group (Group A) included 22 families who were attending the Early Intervention Programme (EIP) during the period 2005-2007 (before the economic crisis) and the second group of participants (Group B) consisted of 25 families attending the same intervention programme in 2011-2013 (during the crisis). They consisted of all of the participants in the EIP during those time periods. In all cases, the children had undergone an interdisciplinary diagnostic procedure and their families had been informed of the results. In Table 1, children's ages, psychosocial and psychiatric diagnoses (according to ICD-10) may be seen for each group. In case of comorbidity, children may have up to three psychiatric diagnoses, while there is no limitation to the number of psychosocial diagnoses. Only two families in Group A and one in Group B were immigrants.

Materials: Data examined from the patients' files were the psychiatric diagnosis, number of siblings and their psychopathology, parents' ages and their educational level and profession, the event of immigration and the family's psychosocial diagnoses according to the ICD-10 (1991). Table 2 presents the psychosocial diagnoses (according to ICD-10).

The research study was approved by the Hospital's Board of Research Ethics. 
Statistical procedures: Data was analyzed with the SAS (2012) statistical package.

Principal components analysis was conducted in order to reduce the number of factors. The criterion for remaining in a principal component was the eigenvalue and the ability to interpret it. This was followed by conducting logistic regression with Z60, Z62, Z63, Z81 and the total Z score as dependent variables, and the principal components which had arisen from the previous analysis including time period as independent variables.

\section{RESULTS}

Table 3 shows the principal components analysis. In an attempt to reduce the number of ten factors, principal components analysis was conducted. Based on the eigenvalue criterion, four principal components (PC) were identified:

PC1: the socio-economic-professional status of the parents

PC2: parents' ages

PC3: number and psychopathology of siblings

PC4: immigration status of parents

These principal components were then analysed further.

Table 4 shows the results of the statistical analysis. In time period A (before the economic crisis) problems related to Z62 diagnoses were less likely to be found. These problems were related to the child's upbringing. Furthermore the total Z score was statistically significant. Psychosocial diagnoses were generally found to be increased during the crisis, and these were specifically related to the parents' difficulties related to child care and upbringing.

Consequently, the two groups did not present statistical differences regarding parents' ages, educational level and profession, and children's diagnoses.

Children's upbringing problems $(\mathrm{p}=0.0163)$ were found to be statistically significant, with the families exhibiting insufficient parental control and supervision, hostile behaviour towards the child, emotional neglect and difficulties in sustaining boundaries during the crisis. The total scores for the psychosocial parameters demonstrated that these families revealed significantly more problems on the whole during the crisis.

None of the Principal Components was found to be specifically correlated with a Z factor. Factor Z60 could not be included in the analysis.

\section{DISCUSSION}

This study refers to families with preschool children with specific developmental disorders, attending an early intervention programme in a public context (Lazaratou \& Vlassopoulou 2006, Vlassopoulos et al 2010). The purpose of the study was to examine the psychologicalsocial consequences of the economic crisis in these families compared to families who attended the same service before the crisis.

The families in both groups were living in the same urban area and their children were in the same diagnostic category of specific developmental disorders. Moreover, the ages of the parents, their educational level, their professions, ages of children, diagnoses, the number and presence of psychopathology in their siblings do not show statistically significant differences between the two groups in the two periods, before and during crisis. The number of immigrant families was also at the same level. Therefore both groups in both periods appear to be 
uniform in terms of their characteristics. Moreover the children in both groups were treated in the early intervention programme under the same conditions.

It must be noted that families in both samples present difficulties regarding their professions, unemployment, housing, socioeconomic problems, dysfunctional marital relationships, familial history of psychiatric and behavioural disturbances and children's upbringing problems. Residents of the areas of responsibility of the Community Centre and especially those attending this programme are generally people with low economic resources, often coping with difficult living conditions. Consequently it must be noted that an increased rate of unemployment was not found between the two groups before and during the economic crisis. Nevertheless, the families of the second group (Group B) experience statistically significant more psychosocial problems (when present), as shown by the total Z scores (Table 4).

The deprived and unemployed population is directly and more heavily affected during an economic crisis, but anxiety and discomfort affects even the part of the population which does not have such experiences. In our sample, increased levels of unemployment were not found, which is an objective anxiogenic parameter, but the families seem to be experiencing employment uncertainty which is subjective, and which can lead to a greater psychological burden. Furthermore, the reduced personal income elicits both the inability to meet financial obligations (objective factor), and negative feelings of insufficient income (subjective factor).

Personality characteristics such as neurosis, low frustration tolerance, a need to control the situation, the general feeling of self-esteem and self-worth are related to an increased vulnerability to a psychosocial threat (Probst, 2005).

Some studies relate family risk factors and their negative influence on the quality of parenting and on parental control which have adverse consequences on children's development. Mental health services can help these parents get reinforced with parent training, and other assistance in order to adopt positive parenting practices to confront their difficulties (Westbrook \& Harden 2010).

In our study, there is a statistically significant difference $(p=0.0163)$ between the two groups, regarding problems associated with child rearing. Specifically, the second group (during the crisis) is facing more problems in this area. Inadequate parental supervision and control, hostility toward the child, emotional neglect of the child and failure to set boundaries are some of the recorded difficulties. Apparently, parents in this situation, where the external world is full of uncertainty and hostility, are unable to rally and present more sensitivity to the needs of children, but instead this situation appears to erode the family net, leaving the child unprotected and exposed and the parents reaching the limits of their endurance.

The economic crisis in Greece seems to have a significant impact on families, not only because they have problems in their daily living, unemployment, and lack of resources, but also because of the consequent uncertainty. For families who have a member or child with difficulties, the situation is even more critical, because apart from the difficulties presented to families at a practical level, the benefits they can offer to their child are significantly reduced. Public hospitals and frameworks have serious problems, funded programmes have stopped operating, and insurance fails to cover part of the costs for the private provision of services. Often families find themselves at a dead-end and cannot meet the needs of their children. 
Nevertheless, in our study increased levels of depression, anxiety, substance abuse, suicides and antisocial behaviour were not recorded as in other studies in the Greek population (Bouras \& Lykouras, 2011, Giotakos, Karabelas \& Kafkas, 2011). In our sample, the insecurity and fear of job loss reflects on the family cohesion and on inappropriate parenting, but not on other psychosocial parameters.

\section{LIMITATIONS}

It is noted that a limitation of the study is the fact that the same families had not been investigated before the crisis in order to identify whether potential dysfunctional behaviour existed prior to the crisis. Nevertheless the fact that these families have the same social and financial characteristics may alleviate this limitative factor.

\section{CONCLUSIONS}

In this study, the emotional and practical difficulties elicited by the economic crisis have a direct impact on the families of small children with specific developmental disorders. These repercussions have an effect on the way the parents deal with issues within the home environment, particularly with a disruptive and dysfunctional impact on their children's upbringing.

In adverse social conditions, in a situation that extends beyond the borders of the family and affects a whole society, parents' capabilities and resilience are stretched and they are unable to protect themselves against the negative consequences of this situation, thereby exposing their children to the risk of developing long-term psychological disorders.

Mental health services are required to fine-tune their interventions to support families' needs, according to the new data presented by the economic crisis. In the Child and Adolescent Service of Community Mental Health Centre Byron-Kessariani, in addition to the Early Intervention Programme regarding the specific developmental disorders of their children, parents are also supported through individual and group sessions focused on the treatment of emotional issues arising from the present economic crisis in the country. It also appears that a systematic monitoring of these families is necessary to establish the long-term consequences and impacts of the crisis over time.

\section{References}

Anagnostopoulos, D.K. \& Soumaki, E. (2012). The impact of socio-economic crisis on mental health of children and adolescents. Psychiatriki, Jan-Mar; 23(1):13-6.

Belsky, J. (1993). Etiology of child maltreatment: A developmental-ecological analysis. Psychological Bulletin, 114, 413-434.

Belsky, J., Fish M. \& Isabella R. (1991). Continuity and discontinuity in infant negative and positive emotionality: Family antecedent and attachment consequences. Developmental Psychology, 27, 421-431.

Bouras, G. \& Lykouras,L. (2011). The economic crisis and its repercussions on mental health. Engefalos, 48:54-61 Butterworth, P., Rodgers, B. \& Windsor, T.D. (2009). Financial hardship, socioeconomic position and depression: results from the PATH Through Life Survey. Soc Sci Med, 69:229-237.

Chalkousi, G., Vlachaki, E., Voulgari, A., Voutirakos, P., Grigoriadou, A. \& Gravani, E. (2012). The effects of the economic crisis on mental health: The experience of the Greek Centre for Mental health and Research. Synapsis, 26, 8:4-8.

Chang, S.S., Stuckler, D., Yip, P. \& Gunnel, D. (2013). Impact of 2008 global economic crisis on suicide: time trend study in 54 countries. BMJ, 347:f5239.

Chatterjee, P. (2009). Economic crisis highlights mental health issues in India. Lancet, 373:1160-116. 
M. V., N. C., F. K., \& H. L. (2016). The Effect of the Economic Crisis on the Functioning of Families with Language-Disordered Children. Advances in Social Sciences Research Journal, 3(11) 204-213.

Economou, M., Peppou, L.E., Louki, E., Komporozos A., Mellou A. \& Stefanis C. (2012). Depression telephone helpline: help seeking during the financial crisis. Psychiatriki, Jan-Mar; 23(1):17-28.

Economou, M. \& Mavreas, V. (2011). The social dimension of depression. Announcement 21st Hellenic Psychiatric Conference, Athens, May.

Fatourou, M. (2010). Job and unemployment: psychological consequences. Encephalos, 47, 4:176-180.

Ferrie, J.E., Shipley, M.J., Marmot, M.G., Stansfeld, S., \& Davey-Smith, G. (1998). The health effects of major organizational change and job insecurity. Soc Sci Med, 46:243-254.

Friedman, J. \& Thomas D. (2009). Psychological health before, during and after the economic crisis: Results from Indonesia. World Bank Economic Review, 23:57-76.

Gabarino, J. (1992). The meaning of poverty in the world of children. American Behavioral Scientist, 35, $220-237$.

Giotakos, O., Tsouvelas, G. \& Kontaxakis, V. (2012). Suicide rates and mental health services in Greece.

Psychiatriki. Jan-Mar; 23(1):29-38.

Giotakos, O., Karabelas, D. \& Kafkas, A. (2011). The impact of the economic crisis on mental health in Greece. Psychiatriki, 22, 2:109-119.

Lazaratou, E. \& Vlassopoulou, M. (2006). Developmental disorders of childhood and mental retardation., Sygramma Psychiatrikis, B vol. (K.Soldatos, L.Lykouras) Vita pub Athens, 537-557.

Lee, S., Guo, W.J., Tsang, A., Mak, A.P.D., Wu, J., Ng, K.L. et al.

(2010). Evidence for the 2008 economic crisis exacerbating depression in Hong Kong. J Affect Disorders 126:125133.

Melchior, M. et al. (2010). Family income and youths' symptoms of depression and anxiety: a longitudinal study of the French GAZEL Youth cohort. Depress Anxiet. Dec; 27(12):1095-103.

Meltzer, H., Bebbington, P., Brugha, T. \& Jenkins, R. (2010). Job insecurity, socio-economic circumstances and depression. Psychol Med, 40:1401-1407.

Paul, K. \& Moser, K. (2009). Unemployment impairs mental health: metaanalyses. J Vocat Behav 2009, 74:264282.

Probst, TM. (2005). Economic stressors. In: Barling J, Kelloway K, Frone M (eds) Handbook of work stress. Thousand Oaks, CA, Sage, 267-297.

Solantaus, T., Leinonen, J. \& Punamaki, R.L. (2004). Children's Mental Health in Times of Economic Recession: Replication and Extension of the Family Economic Stress Model in Finland. Dev Psych 2004, Vol. 40, No. 3, 412429

Stuckler, D. et al. (2009). The public health affect of economic crisis and alternative policy responses in Europe: an empirical analysis. Lancet, 374:315-323.

Vlassopoulou, M., Tsipra, I., Legaki, L. \& Rotsika, V. (2010). Early Intervention Program of children with Specific Developmental Disorders. In Developmental Language Disorders- from basic research to clinical practice (Vogindroukas I, Stavrakaki A, Okalidou A) Epikentro pub, Thessaloniki, 299-321.

Westbrook, T.R. \& Harden, B.J. (2010). Pathways among exposure to violence, maternal depression, family structure, and child outcomes through parenting: a multigroup analysis. Am J Orthopsychiatry. Jul;80(3):386-400.

Table 1. Participant's age, diagnoses (F) and psychosocial diagnoses (Z) according to ICD-10 (1991) by Group

\begin{tabular}{|c|r|c|c|c|c|c|c|}
\hline \multicolumn{4}{|c|}{ GROUP A } & \multicolumn{3}{c|}{ GROUP B } \\
\hline Child & Age & Diagnoses (F) & $\begin{array}{c}\text { Psychosocial } \\
\text { diagnoses } \\
(\mathrm{Z})\end{array}$ & Child & Age & $\begin{array}{c}\text { Diagnoses } \\
(\mathrm{F})\end{array}$ & $\begin{array}{c}\text { Psychosocial diagnoses } \\
(\mathrm{Z})\end{array}$ \\
\hline A1 & $2 ; 5$ & $\begin{array}{c}\text { F80, F80.1 } \\
\text { F82 }\end{array}$ & 0 & B1 & $2 ; 3$ & $\begin{array}{c}\text { F80.2 } \\
\text { F82 }\end{array}$ & Z63.5, Z62.0, Z59, Z63.0 \\
\hline A2 & $2 ; 6$ & F80.2, F82 & 0 & B2 & $2 ; 4$ & $\begin{array}{c}\text { F80.1 } \\
\text { F82 }\end{array}$ \\
\hline A3 & $3 ; 1$ & F80.2, F82 & 0 & B3 & $3 ; 0$ & F80.1 & Z63.0 \\
\hline
\end{tabular}




\begin{tabular}{|c|c|c|c|c|c|c|c|}
\hline & & & & & & F82 & \\
\hline A4 & $3 ; 3$ & F80.2, F94.0 & Z60.3 & B4 & $3 ; 5$ & $\begin{array}{c}\text { F80.2 } \\
\text { F82 }\end{array}$ & $\begin{array}{l}\text { Z81.1, Z63.0, Z72.5, } \\
\text { Z62.4, Z62.3, Z62.8 }\end{array}$ \\
\hline A5 & $3 ; 9$ & F80.2, F82 & 0 & B5 & $3 ; 5$ & $\begin{array}{c}\text { F80.2 } \\
\text { F82 }\end{array}$ & 0 \\
\hline A6 & $3 ; 9$ & F80.2, F82 & $\overline{Z 81.8}$ & B6 & $3 ; 6$ & $\begin{array}{c}\text { F80.2 } \\
\text { F82 }\end{array}$ & Z62.8 \\
\hline A7 & $3 ; 11$ & F80.2, F82 & Z63.0, Z62.0 & B7 & $3 ; 7$ & $\begin{array}{c}\text { F80.1 } \\
\text { F82 } \\
\end{array}$ & $\begin{array}{c}\text { Z62.6, Z81.1, Z81.8, } \\
\text { Z62.3, Z63.0 } \\
\end{array}$ \\
\hline A8 & $4 ; 0$ & F80.2, F82 & 0 & B8 & $3 ; 9$ & $\begin{array}{c}\text { F80.2 } \\
\text { F82 }\end{array}$ & Z63.5, Z81.8 \\
\hline A9 & $4 ; 2$ & $\begin{array}{c}\mathrm{F} 80.1 \\
\text { F82 }\end{array}$ & Z63.0 & B9 & $3 ; 11$ & $\begin{array}{c}\text { F80.2 } \\
\text { F82 }\end{array}$ & Z62.6 \\
\hline A10 & $4 ; 2$ & F80.2 & $\begin{array}{l}\text { Z63.5, Z62.0, } \\
\text { Z91.1 }\end{array}$ & B10 & $4 ; 0$ & $\begin{array}{l}\text { F80.2 } \\
\text { F82 }\end{array}$ & 0 \\
\hline A11 & $4 ; 3$ & F80.2, F82 & 0 & B11 & $4 ; 1$ & $\begin{array}{c}\text { F80.2 } \\
\text { F82 } \\
\end{array}$ & Z62.8, Z56 \\
\hline A12 & $4 ; 5$ & F80.2, F82 & Z62.0 & $\mathrm{B} 12$ & $4 ; 1$ & $\begin{array}{c}\text { F80.2 } \\
\text { F82 }\end{array}$ & Z62.4, Z62.3, Z60.4 \\
\hline A13 & $4 ; 7$ & F80.2, F82 & Z59,Z63.5 & $\mathrm{B} 13$ & $4 ; 4$ & $\begin{array}{c}\text { F80.2 } \\
\text { F82 }\end{array}$ & Z59 \\
\hline A14 & $4 ; 8$ & F80.2, F82 & 0 & B14 & $4 ; 11$ & $\begin{array}{c}\text { F80.2 } \\
\text { F82 } \\
\end{array}$ & Z62.6, Z56, Z63.0 \\
\hline A15 & $5 ; 0$ & F80.2, F82 & Z81.8 & $\mathrm{B} 15$ & $5 ; 2$ & $\begin{array}{c}\text { F80.2 } \\
\text { F82 }\end{array}$ & Z81.1, Z62.6, Z56, Z59 \\
\hline A16 & $5 ; 0$ & F80.2, F82 & Z63.0 & B16 & $5 ; 2$ & $\begin{array}{c}\text { F80.2 } \\
\text { F82 } \\
\end{array}$ & Z63.5, Z59, Z63.3, Z62.4 \\
\hline A17 & $5 ; 2$ & $\begin{array}{c}\text { F80.1, F80.2, } \\
\text { F82, F41.1 }\end{array}$ & 0 & $\mathrm{~B} 17$ & $5 ; 3$ & $\begin{array}{c}\text { F80.2 } \\
\text { F82 }\end{array}$ & Z63.5, Z81.8, Z63.0 \\
\hline A18 & $5 ; 2$ & $\begin{array}{c}\text { F80.1 } \\
\text { F82 }\end{array}$ & Z63.5 & B18 & $5 ; 3$ & $\begin{array}{c}\text { F80.2 } \\
\text { F82 }\end{array}$ & $\begin{array}{c}\text { Z60.3, Z60.4, Z62.4, } \\
\text { Z65.1, Z59, Z62.8 }\end{array}$ \\
\hline A19 & $5 ; 3$ & F80.1, F82 & 0 & B19 & $5 ; 5$ & $\begin{array}{c}\mathrm{F} 80.1 \\
\mathrm{~F} 82\end{array}$ & 0 \\
\hline A20 & $5 ; 4$ & $\begin{array}{c}\text { F80.2 } \\
\text { F82 }\end{array}$ & Z63.0 & $\mathrm{B} 20$ & $5 ; 6$ & $\begin{array}{c}\text { F80.2 } \\
\text { F82 }\end{array}$ & 0 \\
\hline A21 & $5 ; 8$ & $\begin{array}{c}\text { F80.2 } \\
\text { F82 }\end{array}$ & 0 & $\mathrm{~B} 21$ & $5 ; 8$ & $\begin{array}{c}\text { F80.2 } \\
\text { F82 }\end{array}$ & Z62.8 \\
\hline A22 & $5 ; 9$ & F80.2 & Z60.3 & $\mathrm{B} 22$ & $5 ; 8$ & F80.1 & Z63.3 \\
\hline & & & & $\mathrm{B} 23$ & $5 ; 8$ & $\begin{array}{c}\text { F80.1 } \\
\text { F82 }\end{array}$ & 0 \\
\hline & & & & B24 & $5 ; 11$ & F80.2 & Z63.5, Z81.1,Z81.8 \\
\hline & & & & $\mathrm{B} 25$ & $5 ; 11$ & $\begin{array}{l}\text { F80.2, F82, } \\
\text { F91.3 }\end{array}$ & Z62.4, Z63.0, Z62.8 \\
\hline
\end{tabular}

Table 2: Psychosocial diagnoses according to ICD-10 (1992)

\begin{tabular}{|l|}
\hline Z56 - Problems related to employment and unemployment \\
\hline Z59 - Problems related to housing and economic circumstances \\
\hline Z60 - Problems related to social environment \\
\hline Z60.0 Problems of adjustment to life-cycle transitions \\
\hline Z60.1 Atypical parenting situation \\
\hline Z60.2 Problems related to living alone \\
\hline Z60.3 Acculturation difficulty \\
\hline Z60.4 Social exclusion and rejection \\
\hline Z60.5 Target of (perceived) adverse discrimination and persecution \\
\hline Z60.8 Other problems related to social environment \\
\hline Z62 - Problems related to upbringing \\
\hline
\end{tabular}




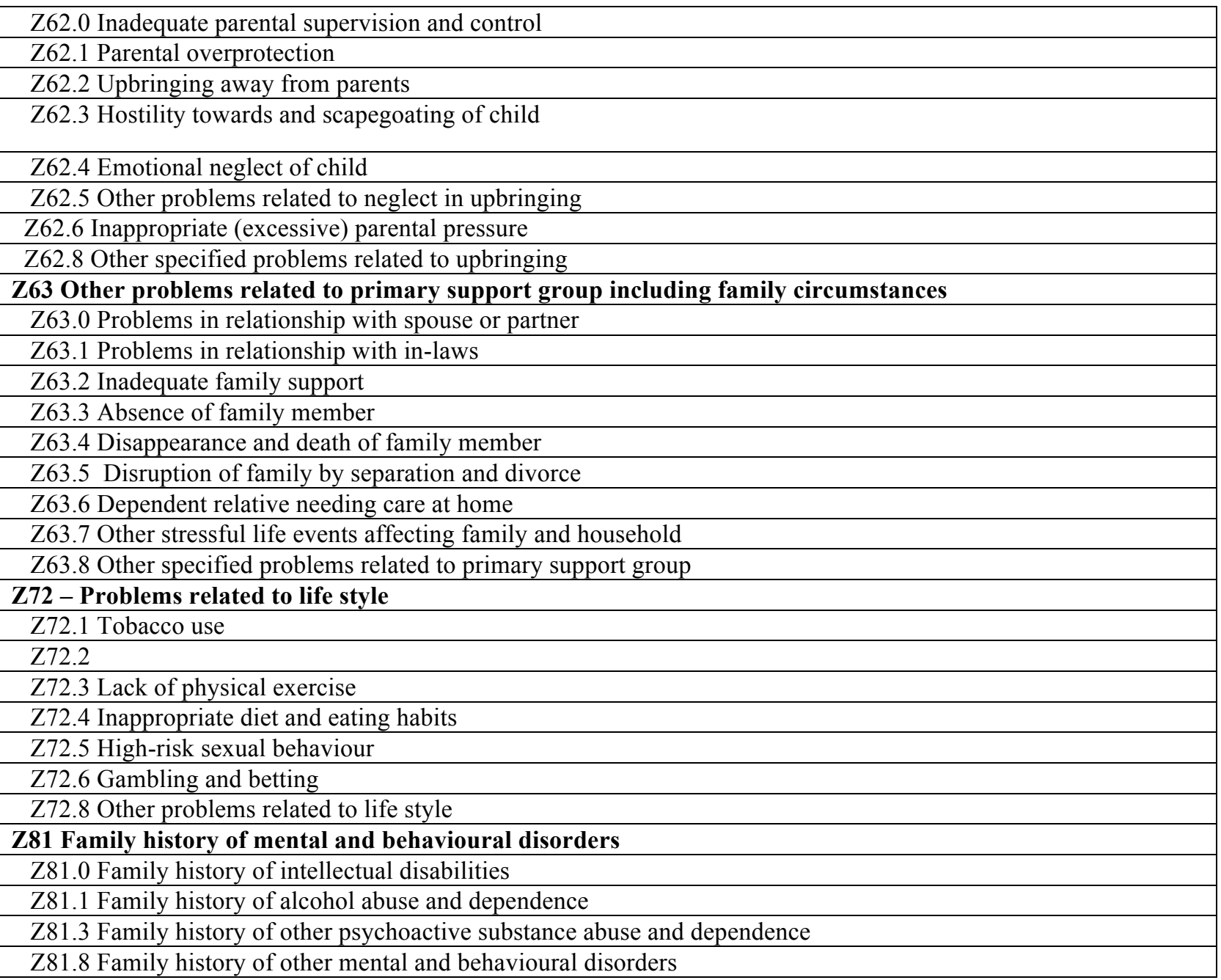

Table 3: Principal Components (PC)

\begin{tabular}{|l|l|l|l|l|}
\hline Principle Variable & PC1 & PC2 & PC3 & PC4 \\
\hline Number of siblings & 15 & 23 & $\mathbf{7 7}^{*}$ & 25 \\
\hline Father's age & -1 & $\mathbf{9 0 *}$ & -5 & 4 \\
\hline Mother's age & -6 & $\mathbf{8 4 *}$ & 12 & -16 \\
\hline Father's profession & $\mathbf{7 7 *}$ & -14 & -5 & 2 \\
\hline Father's education & $\mathbf{8 5 *}$ & 1 & 4 & -33 \\
\hline Mother's profession & $\mathbf{4 5 *}$ & 1 & $\mathbf{- 5 5 *}$ & 24 \\
\hline Mother's education & $\mathbf{8 7 *}$ & -1 & 3 & 3 \\
\hline Immigration & 0 & -12 & 16 & $\mathbf{8 8 *}$ \\
\hline Sibling psychopathology & -6 & -7 & $\mathbf{7 1 *}$ & 5 \\
\hline SES & $\mathbf{8 1 *}$ & 11 & -17 & 37 \\
\hline
\end{tabular}

*factor with a value of over 0.4 
Table 4. Estimate of relative probability (confidence interval 95\%) of the variables Z62, Z63, Z81 and total $\mathrm{Z}$ scores in relation to the Principal Components (PC) and each time period

\begin{tabular}{|c|c|c|c|c|}
\hline \multirow[t]{2}{*}{$\mathrm{PC}$} & \multicolumn{4}{|c|}{ Variables } \\
\hline & Z62 & Z63 & Z81 & Z \\
\hline 1 & $\begin{array}{c}0.904 \\
(0.476-1.176)\end{array}$ & $\begin{array}{c}0.644 \\
(0.349-1.185)\end{array}$ & $\begin{array}{c}1.462 \\
0.591-3.615\end{array}$ & $\begin{array}{c}0.844 \\
(0.493-1.446)\end{array}$ \\
\hline 2 & $\begin{array}{c}1.250 \\
(0.661-2.364)\end{array}$ & $\begin{array}{c}0.956 \\
(0.524-1.744)\end{array}$ & $\begin{array}{c}1.660 \\
(0.706-3.904)\end{array}$ & $\begin{array}{c}0.879 \\
(0.514-1.503)\end{array}$ \\
\hline 3 & $\begin{array}{c}1.569 \\
(0.832-2.956)\end{array}$ & $\begin{array}{c}0.850 \\
(0.465-1.552)\end{array}$ & $\begin{array}{c}0.874 \\
(0.380-2.008)\end{array}$ & $\begin{array}{c}1.160 \\
(0.672-2.001)\end{array}$ \\
\hline 4 & $\begin{array}{c}1.285 \\
(0.689-2.395)\end{array}$ & $\begin{array}{c}0.940 \\
(0.510-1.732)\end{array}$ & $\begin{array}{c}0.475 \\
(0.123-1.838)\end{array}$ & $\begin{array}{c}1.548 \\
(0.903-2.651)\end{array}$ \\
\hline Time Period $=1$ & $\begin{array}{c}0.095 \\
(\mathbf{0 . 0 2 0 - 0 . 4 6 0 )} *\end{array}$ & $\begin{array}{c}0.571 \\
(0.163-2.000)\end{array}$ & $\begin{array}{c}0.225 \\
(0.036-1.405)\end{array}$ & $\begin{array}{c}0.214 \\
(\mathbf{0 . 0 6 6 - 0 . 6 8 8 ) *}\end{array}$ \\
\hline
\end{tabular}

NB: Statistical significance as the value $\geq 1$ 